\title{
Scope versus Speed: Team Diversity, Leader Experience, and Patenting Outcomes for Firms
}

\section{Citation}

Choudhury, Prithwiraj, and Martine R. Haas. "Scope versus Speed: Team Diversity, Leader Experience, and Patenting Outcomes for Firms." Strategic Management Journal 39, no. 4 (April 2018): 977-1002.

\section{Published Version}

10.1002/smj.2753

\section{Permanent link}

http://nrs.harvard.edu/urn-3:HUL.InstRepos:39916993

\section{Terms of Use}

This article was downloaded from Harvard University's DASH repository, and is made available under the terms and conditions applicable to Open Access Policy Articles, as set forth at http:// nrs.harvard.edu/urn-3:HUL.InstRepos:dash.current.terms-of-use\#OAP

\section{Share Your Story}

The Harvard community has made this article openly available.

Please share how this access benefits you. Submit a story.

\section{Accessibility}




\title{
Scope versus Speed:
}

\section{Team Diversity, Leader Experience, and Patenting Outcomes for Firms*}

\author{
Prithwiraj Choudhury \\ Harvard Business School \\ Morgan Hall 497 \\ Soldiers Field Road, Boston, MA 02163, U.S.A. \\ pchoudhury@hbs.edu \\ Martine R. Haas** \\ The Wharton School \\ University of Pennsylvania \\ 3620 Locust Walk, Philadelphia, PA 19104, U.S.A. \\ mrhaas@wharton.upenn.edu
}

tel: 2157461973

fax: 2158980401

\footnotetext{
* Both authors contributed equally to this paper; names are listed alphabetically

**Corresponding author

Acknowledgements: We thank Sea-Jin Chang and our SMJ reviewers for their valuable feedback and guidance throughout the review process. We also thank Paola Criscuolo, Iwan Barankay, David Hsu, Joanne Oxley, Phanish Puranam, Luis Rios, and Jasjit Singh for helpful comments on earlier versions of the manuscript.
} 


\section{RESEARCH SUMMARY}

How does the organization of patenting activity affect a firm's patenting outcomes? We investigate how the composition of patenting teams relates to both the scope of their patent applications and the speed of their patent approvals, by examining the main effects of team members' intra-organizational diversity (based on affiliations with formal organizational units and informal organizational communities) and the moderating effects of team leader experience. We test our moderated mediation model in a sample of 121 teams that filed patents in a Fortune 50 company's India R\&D center between 2005 and 2015, using proprietary employee data combined with newly released micro-data from the USPTO. Our findings illuminate the micro-foundations of innovation in firms by highlighting a tradeoff between organizing patenting activity to maximize scope versus speed.

\section{MANAGERIAL SUMMARY}

Patenting is an important strategic tool that firms can use to protect and create value from their innovations. A firm can benefit from filing a patent application that gives it a wider possible set of claims related to an innovation. It can also benefit from faster approval of a patent application by the Patent Office. However, our study shows that there is a tradeoff between patent application scope and patent approval speed, which creates tensions for the organization of patenting activities inside firms. In particular, we find that the diversity of a patenting team is positively related to patent scope but negatively related to patenting speed, and that these relationships vary with the experience of the team leader.

Keywords: micro-foundations of innovation, patents, scope, speed, team diversity, leader experience, within-firm data 
Patenting is central to innovation in many industries, including information technology, telecoms, automotive, pharmaceuticals, biotechnology, aerospace, oil and gas, and more. Strategy research often views a firm's level of patenting activity as a measure of its innovativeness (e.g., Henderson and Cockburn, 1994; Hall, Jaffe, and Trajtenberg, 2005), yet patenting is more than a convenient measure of innovation output. In many industries, patenting is a key source of competitive advantage, because patents enable firms to fend off competitors and capture the value of their innovations (Kitch, 1977; Spender and Grant, 1996). The potential strategic value of patenting suggests that it is important to understand how patents are generated by firms. This raises a question that has been little explored to date: How does the organization of patenting activity within a firm affect its patenting outcomes?

Scholars have long recognized that much innovation within firms is driven by bottom-up actions of front-line employees (e.g., Bower, 1970; Burgelman, 1983), who identify technical problems to be solved, develop solutions, and champion those solutions (cf. Cyert and March, 1963). Beyond such general insights, however, the micro-foundations of innovative activities like patenting are poorly understood (Felin and Foss, 2005; Foss and Pedersen, 2014). To advance understanding of these micro-foundations, we examine how the composition of patenting teams within a firm relates to the firm's patenting outcomes. We focus on teams because large-scale cross-industry studies have shown that patenting is increasingly team-based (e.g. Singh and Fleming, 2010; Wuchty et al., 2007). Within firms, patenting teams can vary considerably in how they are composed, depending on the characteristics of the members as well as the characteristics of the leaders (i.e., lead inventors). Given this, we investigate how both the membership and leadership of patenting teams relate to patenting outcomes that have potential strategic value for the firm. 
In particular, we examine two patenting outcomes that are closely connected to a firm's ability to capture value from its innovations: patent scope and patenting speed. Firms can benefit from greater patent scope - that is, a patent that covers more of the inventive space - because greater patent scope enables firms to protect and defend more territory from competitors (Kitch, 1977). Firms thus have an incentive to claim as much territory as possible in their patent applications (Lanjouw and Schankerman, 1997). However, firms can also benefit from greater patenting speed, in the form of faster approval of an application by a Patent Office, such as the United States Patent and Trade Office (USPTO), European Patent Office or Japan Patent Office. Most applications are eventually approved in some form (e.g., Carley, Hegde and Marco, 2015). Still, a lengthier adjudication process creates uncertainty about when, whether, and which of the patent's claims might be approved, and can lead to opportunity costs for firms (Harhoff and Wagner, 2009; Gans, Hsu, and Stern, 2008; Farre-Mensa, Hegde, and Ljungqvist, 2016).

Both greater patent application scope and faster patent approval speed thus have potential strategic benefits for firms. Yet there may be a tradeoff between them if applications with more claims take longer to approve, as recent research suggests (e.g., Marco, Sarnoff, and DeGrazia, 2016). To explore this tradeoff between scope and speed, we examine the relationships between the composition of patenting teams and both of these patenting outcomes. We conceptualize the characteristics of team members in terms of two forms of diversity that are particularly relevant inside firms: their affiliations with formal organizational units (e.g. Cummings, 2004) and informal organizational communities (e.g., Brown and Duguid, 1991). We conceptualize the characteristics of team leaders in terms of both their general experience with prior jobs and their specific experience with prior patents (cf. Becker, 1964; Gibbons and Waldman, 2004). We propose a moderated mediation model, where team diversity has a positive direct relationship 
with patent application scope but a negative indirect relationship with patent approval speed, and these positive direct and negative indirect relationships are both moderated by leader experience.

We test these hypotheses using a unique dataset of patents filed by 121 teams in the Indian R\&D center of a Fortune 50 technology company between 2005 and 2015. We collected detailed proprietary intra-firm data on team diversity and leader experience, and matched these with both published patent data and newly-released micro data on the patent examination process from the USPTO. In additional analyses, we conducted an instrumental variable test (using a building relocation event) and a Heckman selection test (using cricket league memberships) to address possible endogeneity concerns in our data. We also explored the mechanisms linking application scope and approval speed more closely; conducted multiple robustness checks to address other data issues; and analyzed additional data on Google's patents to further explore the strategic implications of broader patent scope versus faster patent approval speed for firms.

Our findings offer three contributions to research on patenting by firms and organizational innovation more broadly. First, we show that firms face a tradeoff in organizing their patenting activities, because the same features of team composition that increase patent scope directly also decrease patenting speed indirectly. Second, we advance understanding of the micro-foundations of innovation within firms by showing how team members' group-level attributes (i.e., their diversity) relate to two patenting outcomes with strategic value for the firm (i.e., scope and speed), as well as how these relationships are moderated by team leaders' individual-level attributes (i.e., their experience). Third, our empirical analysis utilizes two rich data sources that are both relatively novel in research on patenting and organizational innovation: detailed intra-firm personnel data and micro-data from the USPTO's patent review records. Thus, our study opens new avenues for exploring the conditions that facilitate patentable innovation by firms. 


\section{ORGANIZING FOR PATENTING}

\section{Patent Scope and Patenting Speed}

The purpose of a patent is to grant the inventor the legal right to appropriate the benefits from their invention for some period of time (Kitch, 1977). To receive a patent, a firm must submit a patent application to a Patent Office for approval. Since patents would have little value if they did not protect inventors against mere variations to the original idea (Scotchmer, 1991), the patent system allows inventors to specify a patent's scope. A patent application thus consists of two components: a specification of the invention, which describes the solution to a technical problem, and a set of claims, each specifying possible improvements or variations that could be made to the invention to adapt it for different uses (Merges and Nelson, 1994; Walker, 1995).

The scope of a patent is typically measured by its number of claims (e.g., Merges and Nelson, 1994; Cohen and Lemley, 2001; Novelli, 2015; Marco et al., 2016). The claims are the heart of a patent, in that they define the breadth, and limits, of the patent's coverage. As Kitch's (1977) prospect theory of patents argues, a higher number of claims can provide an advantage to an inventor firm by acting as a deterrent to competing firms who run higher risks of infringing on at least one of the patent's claims. Researchers have shown that patents with greater scope can also offer other strategic benefits for firms, including increased valuations (e.g., Lerner, 1994), licensing opportunities (e.g., Gambardella, Giuri, and Luzzi, 2007), and commercialization of inventions (e.g., Dechenaux et al. 2008). Given such strategic benefits, firms have incentives to maximize the scope of their patent applications (Lanjouw and Schankerman, 1997).

Although the strategic benefits of patent scope have received more attention from researchers, there are also strategic benefits to be gained from greater patent approval speed. The average time from application to approval at the USPTO is around 3 years (Carley et al., 
2015; Farre-Mensa et al., 2016), but times can range from less than one to more than five years (Popp et al., 2004; Gans et al., 2008). Recent research has begun to show that slower patent approval speeds can prove costly for firms. For example, Gans et al. (2008) found that delays in patent approval reduced the rate of technology licensing agreements between established firms and entrepreneurs in the biotech, electronics, software, and scientific instruments sectors, while Farre-Mensa et al. (2016) found that approval delays were associated with reductions in sales growth, job creation, and the likelihood of going public for startup firms filing first-time patent applications. In addition, because a patent is granted for a fixed duration (usually 20 years) starting from its date of filing, a patent that takes longer to be approved has a shorter remaining duration to run, reducing protection for innovations with long-term value; conversely, innovations with short-term value may be at or near the point of obsolescence before their patent is granted (Kuhn, Roin, and Thompson, 2016). ${ }^{1}$ Not every firm will be concerned about all these possible costs for every patent (cf. Harhoff and Wagner, 2009), but such concerns help to explain why many companies, including large multinationals like Google, are willing to pay a premium to have their patents processed through a high-priority "fast track" at the USPTO (Ho, 2014).

Despite the potential strategic benefits of both greater patent scope and faster patenting speed for firms, researchers have not examined the within-firm antecedents of variation in either scope or speed, or considered the possible tradeoff between them when organizing for innovation. We address these gaps by examining the relationship between team diversity and scope, followed by the relationship between team diversity and speed. We then consider how these relationships are moderated by leader experience. Our conceptual model is summarized in Figure 1.

----- Insert Figure 1 about here ----

\footnotetext{
${ }^{1}$ There are occasional exceptions where the patent term may be adjusted if the Patent Office recognizes that an excessive delay in patent approval is due to its own bureaucratic delays, but these are rare.
} 


\section{Relationships between Team Diversity, Patent Scope, and Patenting Speed}

To file patents that have a larger number of claims, the members of patenting teams must be able to think beyond the particular manifestation of their core invention to identify the full range of possible variations that form the basis of such claims (Novelli, 2015). Many scholars have noted that novel variations are driven by recombination of existing knowledge (e.g., Nelson and Winter, 1982; Kogut and Zander, 1992; Fleming, 2001). Accordingly, the ability of patenting teams to identify more variations to their core invention can be viewed as a function of their members' access to a variety of existing knowledge for recombination (e.g., Singh and Fleming, 2010; Gruber, Harhoff and Hoisl, 2013; Novelli, 2015). ${ }^{2}$

Teams with members who are more diverse are likely to be able to access a greater variety of knowledge for recombination. While there are many possible forms of team diversity (e.g., Reagans and Zuckerman, 2001; Hoisl, Gruber, and Conti, 2017), we focus on two that are particularly relevant for patenting teams inside firms, since they reflect the importance of a firm's formal and informal structure for innovation (e.g., Kleinbaum and Tushman, 2007). First, team members may be officially affiliated with different formal organizational units, such as functional areas, product divisions, or departments, resulting in what is sometimes referred to as "structural diversity" (Cummings, 2004). Second, team members may choose to be affiliated with different informal organizational communities that focus on particular topics in which they have an interest - that is, communities of practice (Brown and Duguid, 1991). For example, employees in a technology firm might join a community that focuses on $\mathrm{C}++$ language design or

\footnotetext{
${ }^{2}$ Most firms that regularly file patent applications employ patent lawyers who facilitate the process of writing up the patent's claims in the appropriate legal language for filing, but it is the inventors who identify the variations that determine the number of claims. Our field interviews at TechMNC confirmed that inventors were the only ones who possessed the expertise necessary to identify the variations to their core invention; the lawyers' role was to prepare the claim text and ensure compliance with the legal statutes related to novelty, usefulness, and non-obviousness.
} 
UNIX migration. Such communities provide informal forums for employees to connect and share knowledge with others who have related expertise, via platforms such as online discussion forums and databases or at face-to-face events (e.g., Haas, Criscuolo, and George, 2015; Hansen and Haas, 2001). While each employee is usually affiliated with only one formal organizational unit, each may be affiliated with multiple informal organizational communities.

Teams whose members belong to more diverse formal units or informal communities are likely to possess a greater variety of expertise, which in turn enables them to generate more novel recombinations of knowledge (e.g., Taylor and Greve, 2006; Singh and Fleming, 2010). These team members also have access to a greater variety of inputs and ideas through their different networks, enhancing their potential creativity and productivity (e.g., Hargadon and Sutton, 1997; Reagans and Zuckerman, 2001). Additionally, such team members may bring a greater variety of opinions and perspectives to their team, enabling them to see more ways to generate breakthroughs and avoid groupthink (Janis, 1972; Singh and Fleming, 2010).

This increased potential for knowledge recombination suggests that patent applications filed by more diverse teams are likely to have greater scope, in the form of a larger number of claims. First, a more diverse team may be able to develop a more complex core invention with a larger theoretically possible set of variations. Second, a more diverse team may be able to generate a larger number of recombinations related to the underlying technology, and thus identify more of the full range of theoretically possible variations to their core invention. Both of these possibilities can result in a larger number of claims in the patent application. It is also possible that more diverse teams file applications with more claims because unobserved characteristics such as project complexity increase both team diversity and patent scope, though 
ultimately more diverse teams must still realize their potential to generate more claims in their patent applications by recombining their knowledge effectively. For these reasons, we predict:

H1: There will be a positive direct relationship between team diversity based on (a) formal organizational units (b) informal organizational communities and patent application scope.

While more intra-organizationally diverse teams are likely to file patent applications with more claims, they are also likely to file patents that have longer approval times, because applications with more claims will tend to take more time to process at the Patent Office (Harhoff and Wagner, 2009; Kuhn et al., 2016; Marco et al., 2016). As a result, there is a tradeoff between patent application scope and patent approval speed. This tradeoff arises because one strategically relevant organizational outcome has consequences for another strategically relevant organizational outcome that may be undesirable (cf., March, 1981; Weick, 1995; Siggelkow and Rivkin, 2006): that is, the first-order outcome of increased team diversity greater patent scope - can have a second-order effect in the form of slower patenting speed.

To understand why there is a tradeoff between application scope and approval speed, consider the process of adjudicating a patent at the USPTO. ${ }^{3}$ When an inventor files for a patent and pays the fee, the application is assigned to an "art unit" for review based on its technology field, and then to one of the patent examiners within that art unit, who is responsible for assessing whether each of the claims in the application meets the legal thresholds for novelty, usefulness, and non-obviousness. To establish this, one of the examiner's main tasks is search for "prior art" related to each claim (i.e., published material including prior patents, inventions, academic papers, books, articles, etc.) to ascertain whether similar claims have already been

\footnotetext{
${ }^{3}$ In describing this process, we focus on the USPTO because this is where the patents in our dataset were filed; the process is similar at other Patent Offices. We draw on prior papers (e.g., Cockburn et al., 2002; Lemley and Sampat, 2008; Frakes and Wasserman, 2016; Farra-Mensa et al., 2016; Marco et al., 2016), supplemented with insights from 15 interviews we conducted at the USPTO with the Commissioner of Patents, his direct reports, and patent examiners.
} 
made. The examiner then issues a preliminary ruling that identifies whether each claim was allowed, rejected, or requires further clarification. The examiner is likely to need more time to prosecute a patent application that includes a greater number of claims because the search process involves studying more prior art, and the ruling will take longer to prepare. An applicant who chooses to continue with patent prosecution can then address the concerns raised, pay an additional fee, and file a request to have the revised application reviewed again. The applicant is likely to need more time to revise an application that includes more claims since this often requires further research into prior art and adding details in the claim text. ${ }^{4}$ The examiner then reevaluates all of the unresolved claims, and may allow them, reject them, or again request further clarifications. The back-and-forth continues until the application is fully approved, or else is abandoned by the applicant (the USPTO rarely rejects patent applications completely). When there are more claims to be assessed by the examiner and supported by the applicant, there are likely to be more rounds of review in total, again increasing the time taken to approve the patent.

As a result of this process, a first-order outcome of greater patent application scope can have a second-order effect of slower patent approval speed. Patenting teams may or may not be aware of the tradeoff between scope and speed, but its implication is that since team diversity is positively related to application scope, and scope is negatively related to speed, team diversity will be negatively related to approval speed. That is, there will be a negative indirect relationship between team diversity and approval speed that is mediated by application scope. Hence:

\footnotetext{
${ }^{4}$ Our interviews at the USPTO indicated that since the patent examiners face both time and resource constraints in searching non-patent sources of prior art such as books, articles, and papers, they often request further clarification or supporting documentation from the applicant. Since a firm's patent lawyers have limited technical knowledge, addressing these requests usually involves asking the team to identify missing prior art and/or appropriate limitations to a contested claim. The team then works with the lawyers to draft a response as to why the claim is still novel.
} 
H2: There will be a negative indirect relationship between team diversity based on (a) formal organizational units (b) informal organizational communities and patent approval speed, mediated by patent application scope.

\section{Moderating Effects of Leader Experience}

We have argued that team diversity will have a positive direct relationship with patent application scope and a negative indirect relationship with patent approval speed. However, both of these relationships may be moderated by the experience of the team leader. The human capital literature highlights the potential value of both general experience, which can be acquired in any job and is valuable across employers, and specific experience, which is acquired in a particular firm and/or by performing a particular task (e.g., Becker, 1964; Gibbons and Waldman, 2004; Molloy and Barney, 2015). Some patent team leaders will have more general and specific experience than others. For example, some will have limited general experience because they are in their first job, while others have held prior jobs; some will have limited specific experience because they are filing their first patent for the firm, while others have filed prior patents. These differences in experience can affect the ability and motivation of team leaders to leverage team diversity for greater patent scope, with further implications for patenting speed.

Leveraging team diversity for greater patent scope will often require skillful investment of time and effort by the team leader, since diversity can lead to coordination costs and cooperation problems that must be managed. For example, team members who belong to different formal units or informal communities frequently have their own specialized vocabularies and "thought worlds" that make it difficult for them to share knowledge and translate insights across boundaries (e.g., Dougherty, 1992; Carlile, 2004), as well as divergent agendas and interests that can lead to conflict (e.g., Cyert and March, 1963). They also tend to have limited exposure to 
each other in meetings or other settings, making it difficult for them to develop trust and mutual knowledge (e.g., Krauss and Fussell, 1990), and they are often busy with other tasks that demand their limited attention (e.g., Cummings and Haas, 2012). Thus, leveraging the full potential of a diverse team for patent scope requires leaders who have both the ability and motivation to do this.

However, inexperienced leaders may have less ability to leverage team diversity to maximize patent scope than experienced leaders. Leaders in their first job, for example, have less experience managing the general challenges that often arise in teamwork, and securing members' full commitment to the team. Leaders who are working on their first patent have less experience managing the specific challenges involved in patenting, such as weighing, balancing and integrating inventors' diverse knowledge, ideas, and perspectives. Furthermore, inexperienced leaders also may be less motivated to leverage team diversity to maximize patent scope. When leaders are inexperienced, there is usually uncertainty about their quality, but such leaders can signal their quality through "quick wins" (Connelly, Serto and Ireland, 2011). Thus, they have strong incentives to demonstrate success quickly, in order to establish a reputation as a high performer (Holmstrom, 1999). Quick wins can also help to boost their confidence and sense of progress in their careers (Amabile and Kramer, 2011). Given these incentives, leaders who have not held another job or patented before may be less motivated to invest the time and effort needed to maximize the potential benefits of team diversity for patent scope; instead, they may be motivated to file a patent application faster, even if its scope is narrower than it could be. They may also suspect that a narrower patent application will be approved faster at the Patent Office. In contrast, experienced leaders have less reason to try to secure patents quickly. In summary, inexperienced leaders may be both less able and less motivated to leverage their team's diversity to maximize patent application scope than experienced leaders. In turn, the 
moderating effect of leader experience on the first-order outcome of patent application scope may have a second-order effect on patent approval speed. If the differences in the scope of applications filed by diverse teams with inexperienced versus experienced leaders are substantial enough, and if application scope affects approval speed as previously argued, then the narrower applications filed by diverse teams with inexperienced leaders should be approved faster than the broader applications filed by diverse teams with experienced leaders. Therefore, we predict:

H3: The positive direct relationship between team diversity and patent application scope will be less positive if the team leader has less prior (a) job experience (b) patenting experience.

H4: The negative indirect relationship between team diversity and patent approval speed will be less negative if the team leader has less prior (a) job experience (b) patenting experience.

\section{METHODS}

Our research setting is the Indian R\&D center of "TechMNC", a Fortune 50 technology company. This R\&D center was established in the late 1990s; by the time of our data collection in early 2008, it had more than 1,300 R\&D employees. To develop insight into the patenting process at TechMNC, we conducted interviews with all 20 senior managers as well as with a sample of 25 mid- and entry-level employees at the India R\&D center. These interviews revealed a bottom-up patenting process where innovation was driven by frontline $\mathrm{R} \& \mathrm{D}$ employees.

TechMNC India's employees primarily worked on writing code for software products, but they could also choose to apply for funding to work on patentable ideas related to generic technologies that might be relevant for the firm's products. The incentives for patenting were strong, since TechMNC had a worldwide corporate policy of patenting all significant innovation during the period of our study, and the India R\&D center followed this policy. These incentives included faster promotions and reputational benefits. One visible manifestation of the importance 
of such benefits were the "patent blocks" awarded to inventors who successfully patented. These were small plastic bricks inscribed with the inventor's name and the title and date of their patent. Inventors displayed these trophies proudly and prominently on their desks for all to see.

Funds for supporting patenting projects were centrally controlled by product managers located at TechMNC's U.S. headquarters. Inventors around the world submitted patentable ideas to the product managers, who reviewed them at quarterly business meetings and decided whether or not to fund them according to the fit with their strategic priorities for their products. To apply for funding, the lead inventor described the idea in detail, outlined the benefits of patenting it to one or more product groups, submitted a prototype and/or other technological details, and requested a dollar amount of funding based on the estimated time needed to develop the idea and the number and mix of collaborators needed to work on it. Thus, a funding request was based on the resources required to buy out employees' time from their day-to-day projects and develop a proof of concept.

Funding was not limited to experienced lead inventors only; employees who were in their first job out of college or had not patented before also regularly applied for and received funding. The lead inventors we interviewed indicated that they had autonomy in deciding whether or not to include other collaborators on a patenting project, as well as who to include, and that these decisions were motivated by technological considerations rather than political or other concerns. As one team leader noted, "No one forces you to add someone to the team... my manager never told me to add his name to a project team to give him a 'free' patent. You only add other people to the project if they know something about the technology or a device that is relevant." Almost all ideas that were funded led to a patent filing (the exceptions were when a lead inventor left the firm). However, the team leaders we interviewed noted that it was difficult to predict the scope of their eventual patent applications from the start. Projects initially viewed as large or complex 
sometimes resulted in narrow applications, whereas those viewed as smaller or more focused sometimes evolved into broad applications. As is common in multinational firms, TechMNC's patent-filing legal team was located in the U.S., and all patents developed worldwide were first filed with the USPTO. Hence, all patents filed by the India R\&D center were U.S. patents.

\section{Dataset}

Our dataset was created by merging, cleaning, and coding data from three separate sources: intrafirm data on the members and leaders of patenting teams at TechMNC India; newly released data on patent examination history from the USPTO's Public Pair database; and publicly available data on U.S. patents from the Thompson Innovation database.

Our unit of observation is a team patent filed by employees of TechMNC India. To construct the dataset, we first identified all 1,315 R\&D employees on the payroll as of the start of 2008, and collected data on these employees' intra-organizational affiliations and work history from the firm's databases. Next, we searched the Thomson Innovation patent database against the dataset of employee names listed in the TechMNC personnel dataset to identify patent applications filed by these employees between 2005 and 2015. In the final step, we used the Public Pair database to match data on the examination history of each patent application. This yielded a dataset of 493 patent applications, of which 405 (82\%) had been granted by the end of 2016. This high approval rate is consistent with prior patent studies (e.g. Lemley and Sampat, 2008). Of these, 194 were team patents - i.e., listed more than one inventor - of which 164 $(85 \%)$ were granted. All the team patents listed inventors from TechMNC India only; there were no inventors from other countries on them. In light of the importance of the team leader in the bottom-up patenting process at TechMNC, we further limited our sample to team patents for which we had complete intra-firm data for the lead inventor. The final sample that we used in our 
main analyses thus included 121 patents, of which 105 (87\%) were granted. We used the more inclusive samples for robustness checks and supplementary analyses. ${ }^{5}$

\section{Scope and Speed Variables}

To measure patent application scope, we coded the total number of claims listed on each of the initial patent applications in our dataset (patent application scope [total claims]). ${ }^{6}$ Total claims usually include both independent claims (which stand on their own) and dependent claims (which refer back to other claims). While most prior studies conceptualize patent scope in terms of total claims, recent research suggests that scope may be better measured using independent claims only (e.g., Marco et al., 2016). We therefore also coded the number of independent claims separately for robustness checks (patent application scope [independent claims]).

To measure patent approval speed, we identified the time taken (in years) for each patents that was ultimately granted to move from initial application to approval. The average time taken in our dataset was 3.2 years, similar to larger-scale patent datasets. To construct our speed variable, we added one to this measure and took its inverse (patent approval speed).

\section{Team Diversity and Leader Experience Variables}

To capture team diversity, we exploited TechMNC's internal records of its employees'

affiliations with the firm's formal units and informal communities. Since the lead inventor was also a team member, the diversity measures include the leader's characteristics.

To measure formal team diversity, we counted the number of functional areas to which the members of each team belonged (formal team diversity). There were 43 functional areas in

\footnotetext{
${ }^{5}$ We conducted t-tests to compare our final sample of 121 team patents to the 73 team patents dropped due to missing team leader data, and found no significant differences on any of the variables in our study. We also conducted robustness checks on our models using the full sample of 194 team patents by omitting the fixed effects for product groups, where the missing data problem was most acute, and found that all results remained statistically significant. ${ }^{6}$ Traditional patent datasets list the number of claims in the approved patent; it is only with the release of the Public Pair dataset that researchers can now establish the number of claims at application. In our dataset, the correlations between number of claims at application and at approval are 0.84 for all patents and 0.83 for team patents.
} 
TechMNC India, reflecting different technological capabilities; each team member belonged to only one. For example, the 'Structured Query Language' area focused on a programming language for relational database management systems; the 'Terminal Server' area focused on technology that allowed devices to connect to a Local Area Network; the 'PC Casual Games' area focused on developing games for PCs, etc.

To measure informal team diversity, we used data on the employees' memberships in TechMNC's worldwide online technical communities, which were used to post information, share knowledge, and plan events on a wide variety of specific technical topics of interest to the firm's employees. For example, 'C/C++/ VC++ Debugging' was a community dedicated to help for debugging errors in programs using these languages; '.NET Developers Forum' was for those with interests in .NET applications; 'UNIX Migration Virtual Team' provided support to employees working on UNIX migration projects. We began by identifying all the technical communities with which each of the 1,315 employees of the Indian R\&D center was voluntarily affiliated. They belonged to a total of 9,456 unique technical communities (on average, each belonged to 62$){ }^{7}$ Next, we calculated the similarity between the affiliations of every pair of individuals in the R\&D center, using a cosine index. ${ }^{8}$ For each patenting team, we then computed the average of the pairwise similarities for all the individuals on the team, and reverse-coded this measure by subtracting from one to construct a diversity variable (informal team diversity).

To measure the team leader's prior job experience, we coded for whether this was the lead inventor's first job out of college (coded as 1) or not (coded as 0) (leader's first job). To capture

\footnotetext{
${ }^{7}$ In addition, the employees belonged to a total of 653 social communities (e.g., based on cricket teams, hometowns, alumni affiliations, etc.) and 2,571 administrative communities (e.g., related to HR, the cafeteria, etc.).

${ }^{8}$ This approach follows the methodology used to measure knowledge relatedness using patent classes (e.g., Breschi et al. 2000); the cosine index accounts not only for whether two employees belonged to the same communities but also for the general tendency for two communities to have overlapping membership.
} 
the team leader's prior patenting experience, we coded for whether this was the lead inventor's first patent at TechMNC (coded as 1) or not (coded as 0) (leader's first patent).

\section{Control Variables}

We included a number of control variables in our models. First, we controlled for team size by counting the number of inventors listed on the patent in the Thomson Innovation database and cross-checking with the Public Pair dataset (team size).

Second, we controlled for the cost of resourcing each patenting team, in terms of buying out the time of the employees to work on the project (team resource cost). Higher resource costs indicated that the project was allocated a larger budget by TechMNC's product managers, perhaps reflecting the quality or promise of the initial funding proposal. Higher resources costs might also reflect underlying team member characteristics such as higher inventor quality, although our field interviews suggested rather that they reflected employee seniority, which often came with managerial responsibilities that tended to create distance from the frontier of technological innovation. Employees at TechMNC India belonged to four main salary bands, identified as 'General Managers', 'Program or Project Managers', 'Software Developers’ and 'Others' (including software code testers, etc.). Though we did not have access to detailed salary data, we were able to obtain relative resource costs for these four salary bands. We scaled resource costs for software developers (the majority group) at 1 , and used the relative resource costs for the other three salary bands to impute the total resource costs for each team.

Third, we controlled for the total number of prior patents granted to the individuals on each team, since teams with more prior patents might include inventors who were of higher quality and/or better at navigating the patent review process (team patenting experience). 
Fourth, we controlled for the number of returnees on each patenting team, where a returnee is an employee of Indian origin who had moved from the United States back to India to work in TechMNC's India R\&D center, as a significant proportion of its employees ( $~ 8 \%)$ had done. Teams with more returnees might better understand the institutional context of filing patents in the U.S., possibly affecting application scope or approval speed (team returnees).

Fifth, we included dummies for the product group to which the leader of each patenting team belonged, to account for any underlying propensities or capabilities for patent application scope or patent approval speed not otherwise captured in our models (product group fixed effects). Employees at TechMNC India belonged to one of six possible product groups, each of which focused on a particular product portfolio: 'Client', 'Server and Tools', 'Business Solutions, 'Entertainment Devices', 'Online Services Business' and 'Corporate.'

Finally, we controlled for the patent's application year, to account for possible variance arising from temporal changes in patent filing strategies at TechMNC or in patent examination policy or practices at the USPTO (year fixed effects). In robustness checks described later, we also controlled for patent attorneys, patent examiners, patent art units, patent classes, and patent thickets. ${ }^{9}$

\section{Analytic Approach}

To test $\mathrm{H} 1 \mathrm{a} / \mathrm{b}$ and $\mathrm{H} 3 \mathrm{a} / \mathrm{b}$, we used Poisson models adjusted for quasi-maximum likelihood estimation and robust standard errors. All models predicting patent application scope were run on the full sample of 121 team patents. To test $\mathrm{H} 2 \mathrm{a} / \mathrm{b}$, we conducted a mediation analysis using structural equation modeling with bootstrapping (e.g., Aguinis, Edwards, and Bradley, 2016). To

\footnotetext{
${ }^{9} \mathrm{We}$ also ran robustness checks using a number of alternative formulations of our explanatory and control variables, including a logged version of patent scope (to account for skewness), an alternative measure of formal team diversity using product groups instead of functional areas; a simpler measure of informal team diversity using number of communities rather than the cosine measure; and a control variable for number of prior team-based patents (to capture inventors' experience with team-based patenting); all results remained robust.
} 
test $\mathrm{H} 4 \mathrm{a} / \mathrm{b}$, we conducted a moderated mediation analysis with bootstrapping (e.g., Hayes 2013;

Preacher, Rucker, and Hayes, 2007). Moderated mediation exists when the value of the indirect effect is conditional on the value of the moderator variable; it is tested by calculating the 'conditional indirect effect' (CIE) at different values of the moderator variable, and computing whether or not the difference between these CIEs is statistically significant. ${ }^{10}$ All models predicting patent approval speed were run on the sub-sample of 105 granted team patents.

\section{RESULTS}

Table 1 reports summary statistics and correlations for the study variables. We computed variance inflation factors (VIFs) for all models; these were less than 10 for all regressions, indicating that multi-collinearity was not a concern.

----- Insert Table 1 and Table 2 about here -----

Table 2 shows the results for $\mathrm{H} 1$, which predicted a positive direct relationship between team diversity and patent application scope. Models 2 and 4 indicate a positive and significant relationship between formal team diversity and total claims at application $(B=0.121, \mathrm{p}<0.01$ and $\mathrm{B}=0.137, \mathrm{p}<0.01$, respectively). Models 3 and 4 indicate a positive and significant relationship between informal team diversity and total claims $(B=1.242, \mathrm{p}<0.01$ and $\mathrm{B}=1.272, \mathrm{p}<0.01$, respectively). Model 5 indicates that these results are robust to using independent claims only to measure patent application scope $(B=0.103, p<0.05$ and $B=0.725, p<0.01$ for formal and informal team diversity, respectively). Thus, $\mathrm{H} 1 \mathrm{a}$ and $\mathrm{H} 1 \mathrm{~b}$ are both supported. ${ }^{11}$ Among the

\footnotetext{
${ }^{10}$ The conditional indirect effect is calculated by estimating the following two equations, where $\mathrm{X}$ is the independent variable, $\mathrm{M}$ is the mediator variable, $\mathrm{W}$ is the moderator variable and $\mathrm{Y}$ is the dependent variable: $M=a_{0}+a_{1} \times X+a_{2} \times W+a_{3} \times X W$ and $Y=b_{0}+b_{1} \times M+b_{2} \times X+b_{3} \times W+b_{4} \times X W$ Hayes (2013) has shown that the conditional indirect effect is equal to the value of $b_{1}\left(a_{1}+a_{3} W\right)$.

${ }^{11}$ To examine the relative effect sizes for formal versus informal diversity in these and subsequent models, in follow-up analyses we standardized these variables and calculated their marginal effects. We found that informal diversity has a consistently larger effect than formal diversity, perhaps because it is a more fine-grained measure that more accurately reflects the knowledge diversity of team members in our research setting.
} 
control variables, the coefficient for team size is positive and significant and the coefficient for team resource cost is negative and significant for all models.

Table 3 reports the results for $\mathrm{H} 2$, which predicted a negative indirect relationship between team diversity and patent approval speed mediated by patent application scope. The results of the bootstrapping mediated regression analysis show that the indirect effects of both formal team diversity and informal team diversity are negative and statistically significant, indicating support for $\mathrm{H} 2$ ( $\mathrm{B}=-0.013, \mathrm{p}<0.05$ and $\mathrm{B}=-0.138, \mathrm{p}<0.01$, respectively). These results are robust to two alternative widely-used tests for mediation, the Sobel test and the Goodman test. They are also robust to using independent claims only as the measure of patent application scope. The results further indicate that the relationship between informal team diversity and approval speed is fully mediated by application scope (i.e., there is no significant direct effect of informal diversity on speed; $B=-0.010$, n.s.) while the relationship between formal team diversity and approval speed is partially though not fully mediated by application scope (i.e., there is also a significant direct effect of formal diversity on speed; $B=-0.026, p<0.05) .{ }^{12}$ In addition, the total effects of formal/informal team diversity and patent application scope are all negative and significant $(B=-0.039, p<0.01 ; B=-0.148, p<0.10 ; B=-0.009, p<0.01$, respectively). Finally, the results show that the direct effect of the mediator variable of patent application scope on patent approval speed is negative and statistically significant, as expected $(B=-0.009, \mathrm{p}<0.01)$.

----- Insert Table 3, Table 4, and Figure 2 about here -----

Table 4 presents the results for $\mathrm{H} 3$, which predicted that the positive direct relationship between team diversity and patent application scope will be less positive if the team leader has

\footnotetext{
${ }^{12}$ A possible explanation for the direct effect of formal diversity on approval speed - i.e., the part of the total effect that is not mediated by application claims - is that more diverse teams took more time to respond to patent examiners' requests for revisions to the patent application during the review process, regardless of the number of claims in the application, perhaps due to the difficulties of coordinating their activities and integrating their inputs.
} 
less prior experience. ${ }^{13}$ Model 2 indicates negative and significant interactions between a leader's first patent and both formal and informal team diversity $(B=-0.233, p<0.01$ and $B=-$ 1.004, $\mathrm{p}<0.05$, respectively). Model 3 indicates negative and significant interactions between a leader's first job and both formal and informal team diversity $(B=-0.222, p<0.05$ and $B=-2.045$, $\mathrm{p}<0.01$, respectively). Models 4 and 5 show that the results using total claims are largely robust to using independent claims only to measure patent application scope $(\mathrm{B}=-0.038$, $\mathrm{p}=\mathrm{n}$.s. and $\mathrm{B}=-$ 0.711, $\mathrm{p}<0.05$ for the leader's first patent interactions; $\mathrm{B}=-0.245, \mathrm{p}<0.01$ and $\mathrm{B}=-1.394, \mathrm{p}<0.01$ for the leader's first job interactions). Thus, we find support for both $\mathrm{H} 3 \mathrm{a}$ and $\mathrm{H} 3 \mathrm{~b}$. We plot these results in Figure 2. The plots show that the slope of the lines depicting the relationships between patent application scope and both formal and informal team diversity are less positive if it is the leader's first job or first patent than if it is not the leader's first job or first patent. We used a simulation-based procedure (King, Tomz, and Wittenberg, 2000) to verify the relative slopes of the lines depicted in Figure 2. This procedure confirmed that the differences in predicted scope at the two values of the moderating variables are statistically significant $(\mathrm{p}<0.05)$ for low and high values of the team diversity variables.

Finally, we report results related to $\mathrm{H} 4$, which predicted that the negative indirect relationship between team diversity and patent approval speed will be less negative if the team leader has less prior experience. We tested this hypothesis by computing the CIEs at different values of our moderator variables and testing the difference between these CIEs (Hayes, 2013). The results indicate mixed support for both $\mathrm{H} 4 \mathrm{a}$ and $\mathrm{H} 4 \mathrm{~b}$. In the moderated mediation tests for

\footnotetext{
${ }^{13}$ To address possible concerns about non-random sorting of experienced versus inexperienced leaders into patenting projects with different ex-ante characteristics, we compared the observable characteristics of projects led by experienced versus inexperienced team leaders. We found no statistically significant differences in means for team size, team resource cost, or team returnees. The only significant difference was for team patenting experience, a variable that is non-significant and has a point estimate close to zero across all models.
} 
H4a, the CIEs become less negative if this is the leader's first job, as expected. For formal team diversity, the CIEs are - 0.011 and 0.002 if this is not versus is the leader's first job. However, the difference between these effects is not significant. For informal team diversity, the CIEs are -0.337 and 0.038 if this is not versus is the leader's first job. The difference between these effects is statistically significant $(\mathrm{Chi} 2=6.060, \mathrm{p}<0.05)$. In the moderated mediation tests for $\mathrm{H} 4 \mathrm{~b}$, the CIEs also become less negative if this is the leader's first patent. For formal team diversity, the CIEs are -0.035 and 0.016 if this is not versus is the leader's first patent. The difference between these effects is significant $(\mathrm{Chi} 2=3.760, \mathrm{p}<0.05)$. For informal team diversity, the CIEs are -0.255 and -0.252 if this is not versus is the leader's first patent. The difference between these effects is not significant. Thus, there is some support though not complete support for both $\mathrm{H} 4 \mathrm{a}$ and $\mathrm{H} 4 \mathrm{~b}$.

\section{Supplementary Analyses}

We conducted a number of supplementary analyses to address possible endogeneity issues in the data, examine the mechanisms underlying the scope-speed relationship, further check for robustness, and explore the strategic implications of the trade-off between scope and speed for firms. ${ }^{14}$

Instrumental variable analysis (using a building relocation event). In developing our H1 arguments, we argued that more diverse teams can generate patent applications with more claims. However, unobserved differences in patenting projects might also have influenced both team diversity and the number of claims generated, such as variation in project complexity. To more firmly establish evidence for a causal effect of team diversity on patent application scope, we conducted an instrumental variable test. From our field interviews at TechMNC's Indian campus, we identified a plausibly exogenous source of variation for team diversity resulting from the opening of a new building on the campus in early 2008 , which led to the relocation of some

\footnotetext{
${ }^{14}$ Results reported here use patent application scope based on total claims; full models are available on request.
} 
employees from the original Buildings 1 and 2 to this new Building 3. Our interviews indicated that relocation could have affected the likelihood of working on diverse teams. Prior to this event, employees in Buildings 1 and 2 were co-located with others who belonged to different formal units and informal communities as well as to the same units and communities. Previous research has shown that co-location facilitates collaborative innovation because it is easier to search for and work with collaborators in a shared location (e.g., Allen, 1977; Catalini, 2017). Co-located employees at TechMNC were able to build relationships over time with others who belonged to different units or communities because their physical proximity increased the potential for spontaneous interactions in elevators or corridors, around water coolers, or in the lunch room (e.g., Kiesler and Cummings, 2002). These relationships could lead them to invite diverse others or be invited by diverse others to join a patenting team. When employees were relocated to Building 3, however, some of the diverse others with whom they had built relationships moved with them, but others did not. Our interviewees indicated that employees quickly established relationships with others whom they did not already know if they belonged to the same unit or communities, but establishing relationships with others who belonged to different units or communities took longer. As a result, employees who had moved to Building 3 were more likely to turn to those who belonged to the same units or communities as themselves when assembling patenting teams, at least until they built relationships with diverse others in their new location, potentially reducing team diversity.

In our instrumental variable analysis, we exploit the exogenous building relocation event by constructing a measure of the fraction of "movers" on the team (i.e. members who had moved to Building 3), which is plausibly correlated to team diversity but not to unobservable project characteristics captured by the error term. Results indicated that this measure was indeed 
correlated with informal diversity (but not with formal diversity). The instrumental variable regressions indicated a strong negative relationship between the fraction of movers on the team and informal diversity in the first stage $(B=-0.066, \mathrm{p}<0.01, \mathrm{~F}$ Statistic=12.2). There was also a positive and statistically significant relationship between the instrumental variable and the dependent variable of patent application scope in the second stage $(B=37.710, p<0.05)$. These relationships were robust to specifications based on whether the team leader was a mover rather than the fraction of movers on the team, to varying windows of time following the move, and to choice of specification (using ivreg 2SLS or ivpoisson GMM). The results of this analysis strengthen our confidence in the relationship between team diversity and patent application scope.

Heckman selection analysis (using cricket league memberships). While our main analyses focused on team patents, we used a Heckman selection model to test whether our coefficient estimates were subject to sample selection bias related to unobserved characteristics of patenting projects undertaken by teams versus solo inventors. To conduct this test, we drew on data about the lead inventor's membership in TechMNC's intra-firm cricket league. We began by constructing an expanded sample that combined our 121 team patents with 130 solo patents for which we had complete data on the lead inventor. Since the bottom-up nature of the patenting process at TechMNC meant that the inventor who secured funding for the project decided whether to assemble a team to work on the patent or to work on it alone, we then constructed a measure of the lead inventor's social connectedness using the data on TechMNC employees' affiliations with the firm's online communities - but this time, with the social communities rather than the technical communities. Specifically, we coded whether or not the lead inventor belonged to a social community that was part of the intra-firm cricket league, since cricket was a very important social activity within TechMNC India. We then re-generated our results using a 
Heckman selection model that predicted whether the patent was filed by a team or by a solo inventor from this social connectedness variable. In robustness checks, we used other predictors such as the lead inventor's tenure and the mover instrument described above. All results indicated that our findings are robust to a Heckman selection model. ${ }^{15}$

Patent mechanisms analysis. In developing our arguments for $\mathrm{H} 2$, we suggested that applications with more claims will take longer to process at the USPTO in part because they will require more revisions to the claim text and involve more rounds of review. We constructed two additional variables from the Public Pair dataset to explore these two mechanisms empirically. For each granted patent, we computed the change in the number of words in the claim text between application and approval, and calculated its inverse hyperbolic sine (to account for both positive and negative values). Additionally, we calculated the number of review rounds prior to patent approval by coding the number of "requests for continued examination" (RCEs). Using OLS with robust standard errors, we found positive and significant relationships between the number of patent application claims and both change in claim text length $(B=0.339, p<0.01)$ and number of RCEs $(\mathrm{B}=0.024, \mathrm{p}<0.05)$. The results are robust to using a Poisson model adjusted for quasi-maximum likelihood estimation. While exploratory only, these analyses help to explain why patent applications with more claims took longer to be approved.

Missing data. Since our intra-firm data were collected in early 2008, some inventors on the patents in our sample were not included in these data. We conducted several robustness checks to address possible measurement concerns related to these missing observations. First, we restricted our patent sample to more limited windows of time, since years closer to 2008 had less missing data. For example, we examined applications filed between 2005 and 2011 (n=97) and

\footnotetext{
${ }^{15}$ The inverse Mills ratio is not significant when added to the regression equation. The p-value of the lambda term is
} 0.98. Following Wooldridge (2010), we do not reject the null hypothesis of no selection bias. 
between 2005 and 2012 ( $\mathrm{n}=113)$. All results for $\mathrm{H1}$ and H3 remained robust, though the smaller sample sizes precluded convergence for the mediation tests in $\mathrm{H} 2$ and $\mathrm{H} 4$. This also alleviates any concerns related to whether the USPTO's move to a first-to-file system in 2013 might have affected our findings. Second, we constructed a variable that captured the fraction of inventors on a patent that matched with inventors listed in our intra-firm dataset, and ran t-tests on observables such as application scope and approval speed at various discrete cut-offs of this variable; we found no statistically significant differences. Third, we progressively limited our sample of team patents to reduce the fraction of inventors not included in the intra-firm data. All results that converged were consistent with our main findings.

Controlling for patent attorneys, examiners, art units, classes, and thickets. First, to address the concern that different patent attorneys might have different patent filing strategies or capabilities (e.g., Somaya, Williamson, and Lorinkova, 2008), we coded the attorneys for each patent in our sample and included fixed effects for each attorney who filed more than one patent in our models; our results remained robust. ${ }^{16}$ Second, because patent examiners might differ in their adjudication approaches, we controlled for examiners who had adjudicated more than one patent in our sample; all results remain robust. Third, because patents assigned to some art units might require more extensive research than those assigned to other art units (e.g., Lemley and Sampat, 2012), we coded for whether or not the art unit was one of the top ten in our sample and controlled for this in our models; all results remained robust. Fourth, because it might take more time to check for prior art on a patent that is classified in multiple patent classes (e.g., Ferguson and Carnabuci, 2017), we controlled for number of patent classes (both CPC and IPC classes at three and four digits); again, all results remained robust. We also checked whether any of the patents in

\footnotetext{
${ }^{16}$ Given our sample size and bootstrapping technique, we could not achieve model convergence if we included fixed effects for every patent attorney; a similar constraint applied for patent examiners and art units.
} 
our sample were part of the USPTO's fast-track program for expedited patent examination, and established that none were (only 16 were filed after 2012, when the program started). Finally, we addressed the possible existence of "patent thickets" and strategic behavior by firms such as patent mining or submarine patenting (Hegde, Mowery, and Graham, 2009; Cockburn et al., 2010), by identifying all continuations and divisionals in our sample using the Public Pair database and excluding them from the models. All results remained robust.

Strategic implications for firms. An important follow-up question that arises from our findings is whether filing narrower patents that are approved faster is less (or more) strategically optimal for TechMNC than filing broader patents that are approved more slowly. While we cannot answer this question definitively in the present study, we conducted a supplementary analysis of patents filed by Google, a comparable firm in the same industry, to address it at least preliminarily. To construct this dataset, we leveraged the fast-track patent examination program ("Track One") introduced by the USPTO under the America Invents Act of 2011. This program permitted assignees to pay a priority fee of $\$ 4,800$ (adjusted to $\$ 4,000$ in 2013) to have the USPTO complete patent prosecution within one year. Our interviews at the USPTO confirmed press reports that the single largest user of this program was Google (e.g., Ho, 2014). We created a dataset of all Google patent applications filed at the USPTO between 2012 and 2014. Google filed 2,089 patents during this period, of which 1,480 were filed using Track One. We examined the scope of these patents, and found a negative relationship between patents filed using Track One and number of claims at approval $(B=-0.863, \mathrm{p}<0.05)$. Thus, Google paid a premium to fasttrack patents with narrower scope, indicating that it viewed such patents as creating value for the firm, and that faster patents can be desirable for firms in the software industry like TechMNC. 
Finally, we conducted one last exploratory analysis on our main dataset of team patents at TechMNC, to examine the relationship between application scope and the eventual likelihood of patent approval. For this analysis we used applications filed up to and including 2010 only, since those filed later may still be undergoing review. The logit results indicated a significant negative relationship between application scope and the probability that a patent was granted $(B=-0.530$, $\mathrm{p}<0.01)$. While further study is needed, this finding is consistent with recent research on largescale patent data (Marco et al. 2016), and it suggests that filing an application with more claims can affect not only the speed with which a patent is granted, but also whether it is granted at all.

\section{DISCUSSION}

Despite the strategic importance of patenting for many firms, we know little about how the organization of patenting activity within a firm affects its patenting outcomes. Our study has aimed to shed light on this question by examining how the composition of patenting teams in a Fortune 50 company relates to the scope of their patent applications and speed of their patent approvals. Our findings show that there is a positive direct relationship between both formal and informal team diversity and application scope, but a negative indirect (i.e., mediated) relationship between both formal and informal team diversity and approval speed. Furthermore, these direct and indirect relationships are moderated by leader experience. Our study thus reveals that teams face a tradeoff because patent applications with more claims take more time to approve, and that leaders manage this tradeoff differently depending on their experience. Taken together, our findings shed light on the micro-foundations of innovation within firms, highlight the tradeoffs involved in organizing for patenting, and demonstrate the value of combining multiple data sources for gaining insight into the conditions that facilitate organizational innovation.

\section{Micro-foundations of Innovation within Firms}


Scholars have long recognized that innovation within firms is often a bottom-up process that starts with front-line employees who develop and champion new initiatives (Bower, 1970; Burgelman, 1983). Similarly, patenting at TechMNC was a bottom-up process that involved R\&D employees identifying and pursuing opportunities to produce inventions. While recognizing the bottom-up nature of much innovation, however, researchers have paid relatively little attention to how a firm's innovation outcomes are affected by the ways in which employees organize themselves to work on innovative activities. Thus, we still have some way to go to understand the micro-foundations of such activities (Felin and Foss, 2005; Foss and Pedersen, 2014).

Our study illuminates the micro-foundations of innovation within firms, and of patenting in particular, in two ways. First, consistent with our within-firm focus, we highlight the importance of two types of diversity with particular relevance for patenting teams inside firms the formal and informal intra-organizational affiliations of their members. Some prior research offers insights into firm-level antecedents of patent scope (though at approval rather than application), such as a firm's investment in related inventive experience (Novelli, 2015), as well as into factors that may influence the organization of patenting activity in non-firm contexts, such as allocation of credit among academic scientists (Bikard et al. 2015). Our study complements such efforts by illuminating team-level antecedents of both patent scope and patenting speed that reflect the formal and informal structure of firms. Thus, our findings offer insights that are particularly salient for firm-based innovation.

Second, our findings also illuminate the interactions between team-level attributes and individual-level attributes - i.e., leaders' general and specific experience - in affecting outcomes with strategic relevance for the firm. Such interactions between different levels of analysis within firms are fundamental contributors to the micro-foundations of firm-level processes and outcomes, 
yet little research has examined them directly (Foss and Pedersen, 2014). Empirically, we show that the effects of team-level diversity on patenting outcomes are moderated by individual-level experience. Conceptually, we suggest that these results reveal how the implications of team-level capabilities for knowledge recombination depend on individual-level ability and willingness to leverage them. Thus, our arguments and findings offer insight into how the micro-foundations of innovation can operate across levels of analysis within a firm (cf. Gupta et al., 2007).

\section{Tradeoffs between Patent Scope and Patenting Speed}

Strategy scholars have long understood the importance of unintended consequences for firms (e.g., March, 1981; Weick, 1995; Siggelkow and Rivkin, 2006). Our findings reveal that the same team composition attributes that can have a positive first-order outcome, in the form of greater patent application scope, also can have a negative second-order effect, in the form of slower approval speed. This second-order effect is not necessarily unanticipated but it is presumably undesirable, since it creates potential strategic costs for firms. Prior research has shown that patent delays can lead to opportunity costs in terms of commercial revenues, sales growth, employee hiring, follow-on innovation, and going public (e.g., Anton and Yao, 2004; Gans et al. 2008; Farre-Mensa et al., 2016). Our supplementary analyses further suggest that firms may incur direct costs from slower patent approval because applications with more claims may require the addition of more text during the review process and more rounds of review before approval, meaning that the firm's inventors and patent staff have to invest extra time and effort in managing the approval process. Moreover, we also find evidence in our data that more claims at application hurt not only approval speed, but also whether a patent was ultimately approved. Greater awareness of such costs is particularly relevant in the light of the trend toward "claim inflation" reported in the patenting literature (e.g., Van Zeebroeck et al., 2009). 
Of course, slower patenting speed may be a tradeoff worth making for the sake of greater patent scope for some firms or in some industries. Prior literature has shown that firms have many reasons to patent, including licensing, preventing imitation, raising finances, preventing lawsuits, and enhancing reputation (Cohen et al., 2000; Graham et al., 2009). These may involve different tradeoffs between scope and speed for different firms. The relative importance of patent scope versus patenting speed is also likely to vary considerably across industries (Harhoff and Wagner, 2009). Kitch's (1977) prospect theory argued that maximizing the scope of patent protection is vital, but this argument seems more applicable today in industries like the life sciences, where the nature of the innovation process makes broad patent scope highly valued (e.g. Fowler, 2017), than in industries like software, where structural characteristics such as short technology lifecycles create incentives for firms to secure faster patents even at the expense of scope (e.g. Cohen and Lemley, 2001). Taken together, these considerations suggest boundary conditions for a bottom-up approach that lets lead inventors decide whether or not to maximize patent scope. Such a strategy may be appropriate for some industries or firms in light of their sources of strategic advantage, while a more top-down approach and interventions from senior managers or from patent lawyers may be preferable in others.

\section{Directions for Future Research}

Our study also contributes to research on the management of innovation within firms, and patenting in particular, by bringing together fine-grained proprietary intra-firm data with publicly available patent data. There is now an extensive literature examining patenting by populations of firms in particular industries, as well as by academic and scientific communities (e.g. Henderson et al., 1998; Hall and Ziedonis, 2001; Azoulay et al., 2009), but there is still relatively little indepth study of variation in patenting outcomes within individual firms (for exceptions, see 
Nerkar and Paruchuri 2005; Choudhury, 2017). Our study complements the literature on firmlevel antecedents of patenting (e.g., Novelli, 2015), and heeds calls for more in-depth research on patenting within firms (e.g., Singh, 2008: 93) by utilizing new proprietary and public data sources to examine the within-firm antecedents of patent application scope and patent approval speed, two outcomes that have not previously been examined in this research.

While our study thus opens new avenues for future research, some limitations of our empirical approach should be noted. Since our data were collected from a single technology firm, our findings should be confirmed in other firms and industries to establish their generalizability. Because teams at TechMNC India were self-organizing rather than randomly assigned to patenting projects, we cannot definitively establish causality in the relationships between team diversity and patenting outcomes, although our supplementary analyses help to address concerns about unobserved heterogeneity in the data. Additionally, our dataset did not include information on how long teams worked on their patenting projects prior to filing an application. Future research could complement our study by examining this component of the innovation process within firms.

Our study also suggests a number of other directions worthy of further exploration. For example, to delve more deeply into the effects of team composition, future research could collect more detailed information on how much time each inventor allocated to the patent, to better ascertain how team composition effects may depend on full-time versus part-time membership. Other potentially important contributors to the micro-foundations of innovation like organizational incentives, culture, and firm strategy did not vary in our setting, but might vary across firms and influence patenting outcomes. The benefits of organizing for scope versus speed might also vary depending on firm size, age, and industry, with implications for the extent to which firms should 
implement more top-down versus bottom-up approaches to patenting. Exploring such sources of variation for firms could provide valuable insights for both scholars and practitioners.

\section{Conclusion}

We started this study by asking how the organization of patenting activities within a firm can affect the firm's patenting outcomes. Our findings show that teams with more formally and informally diverse members filed patents that had broader application scope but slower approval speed, although these relationships depended on the general and specific experience of the team

leaders. Taken together, these findings illuminate the micro-foundations of innovation within firms, and call attention to the tradeoffs that teams face between organizing patenting activity to maximize scope versus speed. Recognizing the existence and possible ramifications of such tradeoffs points to promising directions for further exploration and possible intervention. 


\section{REFERENCES}

Aguinis H, Edwards JR, Bradley KJ. 2016. Improving our understanding of moderation and mediation in strategic management research. Organizational Research Methods 1: 21. Allen TJ. 1977. Managing the Flow of Technology. MIT Press: Cambridge, MA.

Amabile T, Kramer S. 2011. The progress principle: Using small wins to ignite joy, engagement, and creativity at work. Harvard Business Press: Boston, MA.

Anton JJ, Yao DA. 2004. Little patents and big secrets: managing intellectual property. RAND Journal of Economics 35(1):1-22.

Azoulay P, Zivin JSG, Wang J. 2010. Superstar extinction. The Quarterly Journal of Economics 125: 549-589.

Azoulay P, Ding W, Stuart T. 2009. The impact of academic patenting on the rate, quality and direction of (public) research output. Journal of Industrial Economics 57(4): 637-667.

Baron RM, Kenny DA. 1986. The moderator-mediator variable distinction in social

psychological research: Conceptual, strategic, and statistical considerations. Journal of

Personality and Social Psychology 51(6): 1173-1182.

Becker, GS. 1964. Human capital: a theoretical and empirical analysis, with special reference to education. NY: National Bureau of Economic Research.

Bikard M, Murray F, and Gans JS. 2015. Exploring trade-offs in the organization of scientific work: Collaboration and scientific reward. Management Science 61(7):1473-1495.

Bower JL. 1970. Managing the Resource Allocation Process: A Study of Corporate Planning and Investment. Harvard Business School, Division of Research: Boston, MA.

Breschi S, Malerba F, Orsenigo L. 2000. Technological regimes and Schumpeterian patterns of innovation. The Economic Journal 110(463): 388-410.

Brown JS, Duguid P. 1991. Organizational learning and communities-of-practice: Toward a unified view of working, learning, and innovation. Organization Science 2(1): 40-57.

Burgelman RA. 1983. A model of the interaction of strategic behavior, corporate context, and the concept of strategy. Academy of Management Review 8(1): 61-70.

Carley M, Deepak H, Alan M. 2015. What is the probability of receiving a U.S. patent? Yale Journal of Law and Technology 17(1): 203-23.

Carlile PR. 2004. Transferring, translating, and transforming: An integrative framework for managing knowledge across boundaries. Organization Science 15(5): 555-568.

Catalini C. 2017. Microgeography and the direction of inventive activity. Management Science (Articles in Advance): 1-17.

Choudhury P. 2017. Innovation outcomes in a distributed organization: Intrafirm mobility and access to resources. Organization Science 28(2): 339-354.

Cockburn IM, MacGarvie MJ, Mueller E. 2010. Patent thickets, licensing and innovative performance. Industrial and Corporate Change 19(3): 899-925.

Cockburn IM, Kortum S, Stern S. 2002. Are all patent examiners equal? The impact of examiner characteristics. NBER Working Paper 8980, National Bureau of Economic Research, Cambridge, MA. Cohen WM, Nelson RR, Walsh JP. 2000. Protecting their intellectual assets: Appropriability conditions and why US manufacturing firms patent (or not). NBER working paper 7552, National Bureau of Economic Research, Cambridge, MA.

Cohen JE, Lemley MA. 2001. Patent scope and innovation in the software industry. California Law Review 89(1): 1-57.

Connelly BL, Certo ST, Ireland RD. 2011. Signaling theory: A review and assessment. Journal of Management 37(1): 39-67. 
Cummings JN, Haas MR. 2012. So many teams, so little time: Time allocation matters in geographically dispersed teams. Journal of Organizational Behavior 33(3): 316-341.

Cummings, JN. 2004. Work groups, structural diversity, and knowledge sharing in a global organization. Management Science 50(3): 352-364.

Cyert, R.M. and March, J.G., 1963. A Behavioral Theory of the Firm. Englewood Cliffs, NJ, 2.

Dechenaux E, Goldfarb B, Shane S, Thursby M. 2008. Appropriability and commercialization:

Evidence from MIT inventions. Management Science 54(5): 893-906.

Dougherty D. 1992. Interpretive barriers to successful product innovation in large firms.

Organization Science, 3(2):179-202.

Farre-Mensa J, Hegde D, Ljungqvist A. 2016. The bright side of patents. NBER Working Paper 21959, National Bureau of Economic Research, Cambridge, MA.

Ferguson JP, Carnabuci G. 2017. Risky recombinations: Institutional gatekeeping in the innovation process. Organization Science 28(1): 133-151.

Felin T, Foss NJ. 2005. Strategic organization: A field in search of micro-foundations. Strategic Organization 3(4): 441-455.

Fleming L. 2001. Recombinant uncertainty in technological search. Management Science 47(1): 117-132.

Foss NJ, Pedersen T. 2014. Micro-foundations in strategy research. Strategic Management

Journal 37(13): E22-E34.

Fowler N. 2017. The trials and tribulations of pharmaceutical IP management. American

Pharmaceutical Review 16 March: http://www.americanpharmaceuticalreview.com/Featured-

Articles/335149-The-Trials-and-Tribulations-of-Pharmaceutical-IP-Management/.

Frakes M, Wasserman MF. 2016. Empirical scholarship on the prosecution process at the Patent

Office (PTO). In Research Handbook on the Law and Economics of Intellectual Property,

Menell PS, Schwartz DL, Depoorter B (eds). Edgar Elgar Publishing: Durham, North Carolina.

Gans JS, Hsu DH, Stern S. 2008. The impact of uncertain intellectual property rights on the

market for ideas: Evidence from patent grant delays. Management Science 54(5): 982-997.

Gambardella A, Giuri P, Luzzi A. 2007. The market for patents in Europe. Research

Policy 36(8): 1163-1183.

Gibbons R, Waldman M. 2004. Task-specific human capital. American Economic Review 203-207.

Graham, SJH, Merges RP, Samuelsen P. 2009. High technology entrepreneurs and the patent system:

Results of the 2008 Berkeley patent survey. Berkeley Technology Law Journal 24(4):1255-1327.

Gruber M, Harhoff D, Hoisl K. 2013. Knowledge recombination across technological

boundaries: scientists vs. engineers. Management Science 59(4): 837-851.

Gupta AK, Tesluk PE, Taylor MS. 2007. Innovation at and across multiple levels of analysis.

Organization Science 18(6): 885-897.

Haas MR, Criscuolo P, George G. 2015. Which problems to solve? Online knowledge sharing and attention allocation in organizations. Academy of Management Journal 58(3): 680-711. Hall BH. 2005. Exploring the patent explosion. Journal of Technology Transfer 30(1-2): 35-48. Hall BH, Jaffe A, Trajtenberg M. 2005. Market value and patent citations. Rand Journal of Economics 36(1):16-38.

Hall BH, Ziedonis RH. 2001. The patent paradox revisited: an empirical study of patenting in the US semiconductor industry, 1979-1995. RAND Journal of Economics 32(1): 101-128.

Hansen MT, Haas MR. 2001. Competing for attention in knowledge markets: Electronic document dissemination in a management consulting company. Administrative Science Quarterly 46: 1-28. Hargadon A, Sutton RI. 1997. Technology brokering and innovation in a product development firm. Administrative Science Quarterly 42(4): 716-749. 
Harhoff D, Wagner S. 2009. The duration of patent examination at the European Patent Office. Management Science 55(12): 1969-1984.

Hausman JA, Hall BH, Griliches Z. 1984. Econometric models for count data with an application to the patents-R\&D relationship. NBER Working Paper 0017, National Bureau of Economic Research, Cambridge, MA. Available at: http://www.nber.org/papers/t0017.pdf Hayes AF. 2013. Introduction to Mediation, Moderation, and Conditional Process Analysis: A Regression-based Approach. The Guilford Press: New York. Hayes AF. 2009. Beyond Baron and Kenny: Statistical mediation analysis in the new millennium. Communication Monographs 76(4): 408-420. Hegde D, Mowery DC, Graham SJH. 2009. Pioneering inventors or thicket builders: Which U.S. firms use continuations in patenting? Management Science 55(7): 1214-1226.

Henderson R, Jaffe AB, Trajtenberg M. 1998. Universities as a source of commercial technology: a detailed analysis of university patenting, 1965-1988. Review of Economics and Statistics 80(1): 119-127.

Henderson R, Cockburn I. 1994. Measuring competence? Exploring firm effects in pharmaceutical research. Strategic Management Journal 15(1): 63-84.

Ho C. 2014. Google has gotten more fast track patents than any other company. The Washington Post. October 26.

Hoisl K, Gruber M, Conti A. 2017. R\&D team diversity and performance in hypercompetitive environments. Strategic Management Journal 38(7): 1455-1477.

Holmstrom B. 1999. Managerial incentive problems-A dynamic perspective. Review of Economic Studies 66(1): 169-182.

Janis IL. 1972. Victims of Groupthink: A Psychological Study of Foreign-Policy Decisions and Fiascoes. Houghton Mifflin: Boston, MA.

Kiesler S, Cummings JN. 2002. What do we know about proximity and distance in work groups? In P. J. Hinds, S. Kiesler (eds). Distributed Work. MIT Press, Cambridge, MA: 57-80. King, G, Tomz M, and Wittenberg J. 2000. Making the most of statistical analyses: Improving interpretation and presentation. American Journal of Political Science 44(2): 347-361. Kitch EW. 1977. The nature and function of the patent system. The Journal of Law and Economics 20(2): 265-290.

Kleinbaum AM, Tushman ML. 2007. Building bridges: The social structure of interdependent innovation. Strategic Entrepreneurship Journal, 1: 103-122.

Kogut B, Zander U. 1992. Knowledge of the firm, combinative capabilities, and the replication of technology. Organization Science 3(3): 383-397.

Krauss RM, Fussell SR. 1990. Mutual knowledge and communicative effectiveness. In Intellectual teamwork: Social and technological foundations of cooperative work, Gelegher J, Kraut A, Egido (eds). Lawrence Erlbaum: Hillsdale, NJ; 111-146.

Kuhn JM, Roin, BN, Thompson NC. 2016. Causal inference on patent protection. Working Paper. Available at: http://jeffreymkuhn.com/wp-content/uploads/2016/09/Patent_Metrics.2016.09.20.pdf Lanjouw JO, Schankerman M. 1997. Stylized facts of patent litigation: Value, scope and ownership. NBER working paper 6297, National Bureau of Economic Research, Cambridge, MA. Available at: http://www.nber.org/papers/w6297.pdf Lemley MA, Sampat BN. 2008. Is the Patent Office a rubber stamp? Emory Law Journal 58(1): 181-209. Lemley MA, Sampat BN. 2012. Examiner characteristics and patent office outcomes. Review of Economics and Statistics 94(3): 817-827. 
Lerner J. 1994. The importance of patent scope: an empirical analysis. The RAND Journal of Economics 25(2): 319-333.

March JG. 1981. Footnotes to organizational change. Administrative Science Quarterly 26(4): 563-577. Marco AC, Sarnoff JD, deGrazia C. 2016. Patent claims and patent scope. USPTO Economic Working Paper 2016-04. United States Patent and Trademark Office, Washington D.C.

Merges RP, Nelson RR. 1994. On limiting or encouraging rivalry in technical progress: the effect of patent scope decisions. Journal of Economic Behavior \& Organization 25(1): 1-24. Molloy JC, Barney JB. (2015). Who captures the value created with human capital? A marketbased view. The Academy of Management Perspectives 29(3): 309-325.

Nelson RR, Winter SG. 1982. The Schumpeterian tradeoff revisited. The American Economic Review 72(1): 114-132.

Nerkar A, Paruchuri S. 2005. Evolution of R\&D capabilities: The role of knowledge networks within a firm. Management Science 51(5): 771-785.

Novelli E. 2015. An examination of the antecedents and implications of patent scope. Research Policy 44(2): 493-507.

Popp D, Juhl T, Johnson, DKN. 2004. Time in purgatory: Determinants of the grant lag for U.S. patent applications. Topics of Economic Analysis Policy 4(1): 29.

Preacher KJ, Rucker DD, Hayes AF. 2007. Addressing moderated mediation hypotheses: Theory, methods, and prescriptions. Multivariate Behavioral Research 42(1): 185-227.

Reagans R, Zuckerman EW. 2001. Networks, diversity, and productivity: The social capital of corporate R\&D teams. Organization Science 12(4): 502-517.

Scotchmer S. 1991. Standing on the shoulders of giants: cumulative research and the patent law. The Journal of Economic Perspectives 5(1): 29-41.

Shapiro C, 2000. Navigating the patent thicket: Cross licenses, patent pools, and standard setting. In Innovation policy and the economy, Jaffe A, Lerner J, Stern S (eds). 1 119-150. Shaver JM. 2005. Testing for mediating variables in management research: Concerns, implications, and alternative strategies. Journal of Management 31(3): 330-353.

Siggelkow N, Rivkin JW. 2006. When exploration backfires: Unintended consequences of multilevel organizational search. Academy of Management Journal 49(4): 779-795.

Singh J, Fleming L. 2010. Lone inventors as sources of breakthroughs: Myth or reality? Management Science 56(1): 41-56.

Singh J. 2008. Distributed R\&D, cross-regional knowledge integration and quality of innovative output. Research Policy 37(1): 77-96.

Somaya D, Williamson IO, Lorinkova N. 2008. Gone but not lost: The different performance impacts of employee mobility between cooperators versus competitors. Academy of Management Journal 51(5): 936-953.

Spender JC, Grant RM. 1996. Knowledge and the firm: Overview. Strategic Management Journal 17(2): 5-9. Taylor A, Greve HR. 2006. Superman or the fantastic four? Knowledge combination and experience in innovative teams. Academy of Management Journal 49(4): 723-740.

Van Zeebroeck N, Vanvan Pottelsberghe de la Potterie B, Guellec D. 2009. Claiming more: the increased voluminosity of patent applications and its determinants. Research Policy 38(6): 1006-1020. Walker RD. 1995. Patents as scientific and technical literature. Metuchen, JN: Scarecrow Press Weick KE. 1995. Sensemaking in Organizations. Thousand Oaks, CA; Sage: London. Wooldridge JM. 2010. Econometric Analysis of Cross Section and Panel Data. MIT Press. Wuchty S, Jones BF, Uzzi B. 2007. The increasing dominance of teams in production of knowledge. Science 316(5827): 1036-1. 
Figure 1. Conceptual Model

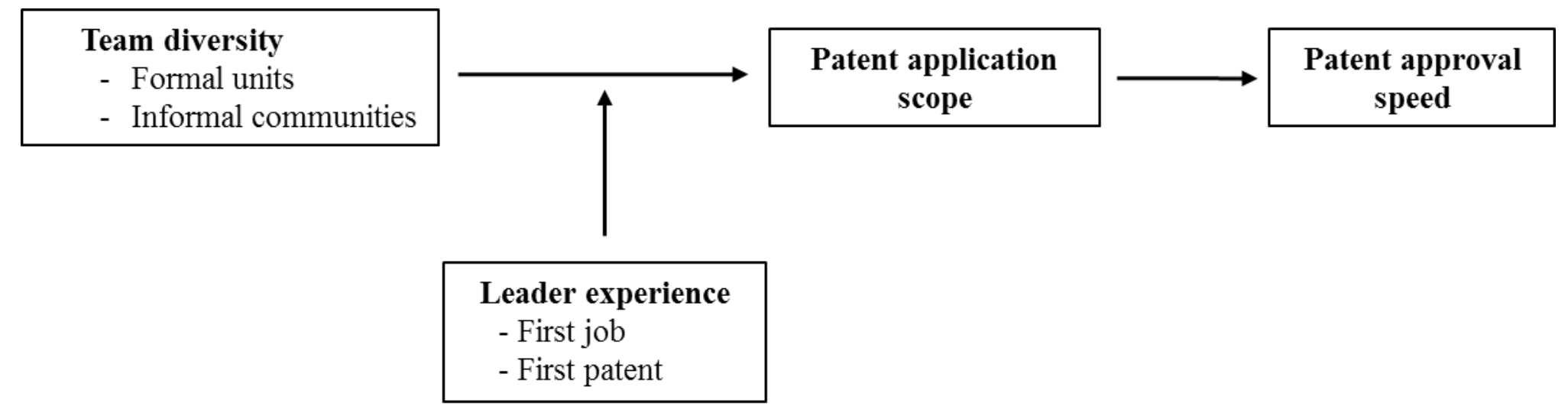


Figure 2. Interaction Plots for Moderating Effects of Leader Experience on Relationships between Team Diversity and Patent Application Scope

(a) Moderating Effects of Leader's Prior Job Experience
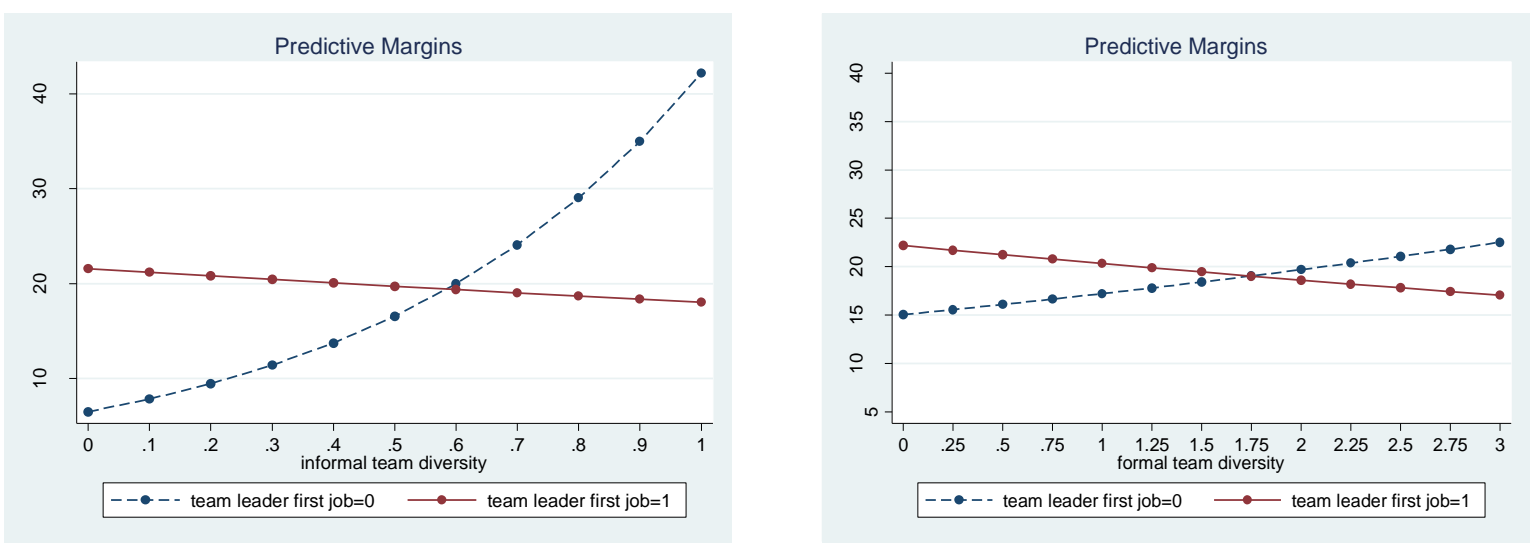

(b) Moderating Effects of Leader's Prior Patenting Experience
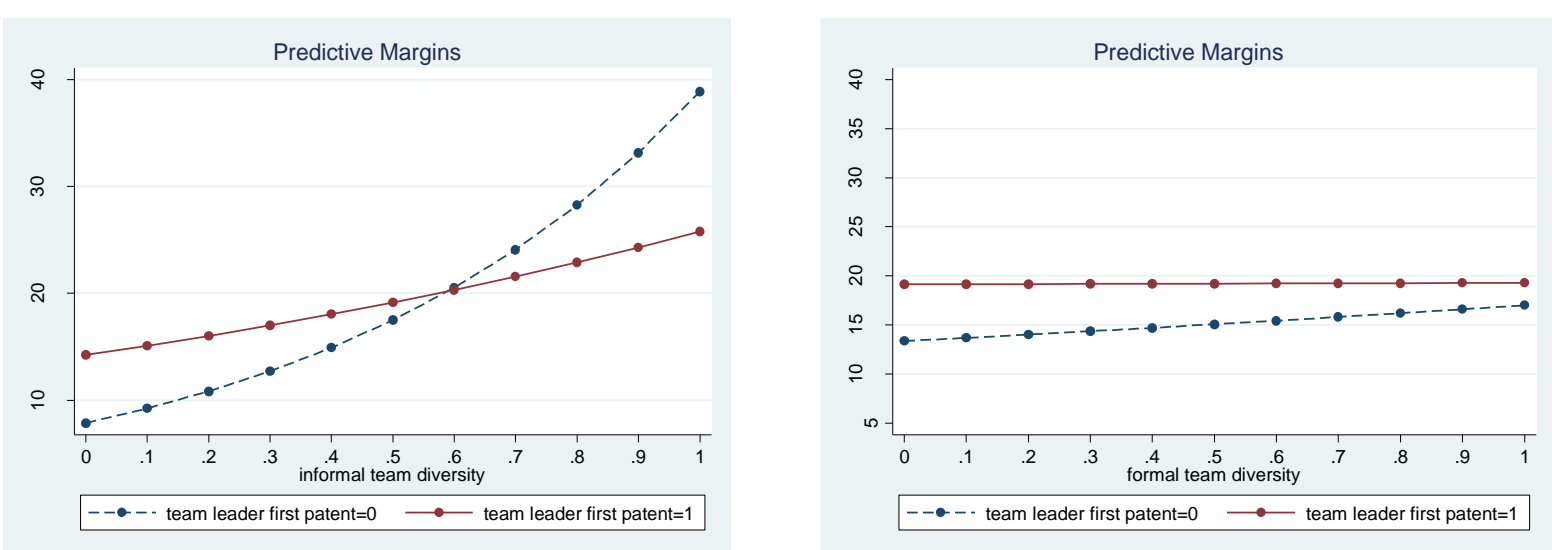
Table 1. Summary Statistics

\begin{tabular}{|c|c|c|c|c|c|c|c|c|c|c|c|c|c|c|c|c|}
\hline Variable & Obs & Mean & $\begin{array}{l}\text { Std. } \\
\text { Dev. }\end{array}$ & Min & Max & 1 & 2 & 3 & 4 & 5 & 6 & 7 & 8 & 9 & 10 & 11 \\
\hline patent approval speed $^{\bar{\top}}$ & 105 & 0.275 & 0.142 & 0.111 & 1.000 & 1 & & & & & & & & & & \\
\hline $\begin{array}{l}\text { patent application scope } \\
\text { [total claims] }\end{array}$ & 121 & 18.430 & 5.485 & 1.000 & 32.000 & -0.533 & 1 & & & & & & & & & \\
\hline $\begin{array}{l}\text { patent application scope } \\
\text { [independent claims] }\end{array}$ & 121 & 2.802 & 0.627 & 1.000 & 5.000 & -0.530 & 0.863 & 1 & & & & & & & & \\
\hline formal team diversity & 121 & 1.306 & 0.530 & 1.000 & 3.000 & -0.210 & 0.201 & 0.234 & 1 & & & & & & & \\
\hline informal team diversity & 121 & 0.509 & 0.140 & 0.000 & 0.760 & -0.434 & 0.526 & 0.436 & 0.132 & 1 & & & & & & \\
\hline leader's first job & 121 & 0.190 & 0.394 & 0.000 & 1.000 & 0.017 & 0.139 & 0.120 & -0.121 & -0.296 & 1 & & & & & \\
\hline leader's first patent & 121 & 0.256 & 0.438 & 0.000 & 1.000 & -0.134 & 0.099 & 0.186 & 0.162 & 0.028 & -0.043 & 1 & & & & \\
\hline team size & 121 & 2.678 & 1.018 & 2.000 & 6.000 & -0.159 & 0.193 & 0.212 & 0.107 & -0.028 & 0.424 & -0.019 & 1 & & & \\
\hline team resource cost & 121 & 1.123 & 0.200 & 0.750 & 2.000 & 0.160 & -0.177 & -0.160 & 0.106 & 0.042 & 0.056 & -0.089 & 0.216 & 1 & & \\
\hline team patenting experience & 121 & 8.744 & 9.651 & 0.000 & 38.000 & 0.134 & 0.077 & 0.020 & -0.114 & -0.101 & 0.243 & -0.365 & 0.306 & -0.014 & 1 & \\
\hline team returnees & 121 & 0.314 & 0.606 & 0.000 & 2.000 & -0.014 & 0.180 & 0.100 & -0.042 & 0.002 & 0.516 & -0.086 & 0.584 & 0.289 & 0.329 & 1 \\
\hline
\end{tabular}

${ }^{\bar{\top}}$ Summary statistics reported refer to granted patents only 
Table 2. Relationships between Team Diversity and Patent Application Scope

\begin{tabular}{|c|c|c|c|c|c|}
\hline & \multicolumn{4}{|c|}{$\begin{array}{c}\mathrm{DV}=\text { Patent } \\
\text { application scope } \\
\text { [total claims] }\end{array}$} & \multirow{2}{*}{$\begin{array}{c}\text { DV = Patent } \\
\text { application scope } \\
\text { [independent claims] } \\
\text { Model 5 }\end{array}$} \\
\hline & Model 1 & Model 2 & Model 3 & Model 4 & \\
\hline Team size & $\begin{array}{c}0.070 \\
(0.027)\end{array}$ & $\begin{array}{c}0.048 \\
(0.027)\end{array}$ & $\begin{array}{c}0.074 \\
(0.026)\end{array}$ & $\begin{array}{c}0.052 \\
(0.025)\end{array}$ & $\begin{array}{c}0.052 \\
(0.016)\end{array}$ \\
\hline Team resource cost & $\begin{array}{l}-0.350 \\
(0.138)\end{array}$ & $\begin{array}{l}-0.428 \\
(0.139)\end{array}$ & $\begin{array}{l}-0.451 \\
(0.125)\end{array}$ & $\begin{array}{l}-0.551 \\
(0.130)\end{array}$ & $\begin{array}{l}-0.321 \\
(0.080)\end{array}$ \\
\hline Team patenting experience & $\begin{array}{l}-0.002 \\
(0.002)\end{array}$ & $\begin{array}{c}0.000 \\
(0.002)\end{array}$ & $\begin{array}{c}0.001 \\
(0.002)\end{array}$ & $\begin{array}{c}0.002 \\
(0.002)\end{array}$ & $\begin{array}{l}-0.001 \\
(0.001)\end{array}$ \\
\hline Team returnees & $\begin{array}{c}0.015 \\
(0.057)\end{array}$ & $\begin{array}{c}0.035 \\
(0.056)\end{array}$ & $\begin{array}{c}0.018 \\
(0.050)\end{array}$ & $\begin{array}{c}0.037 \\
(0.047)\end{array}$ & $\begin{array}{l}-0.012 \\
(0.036)\end{array}$ \\
\hline Formal team diversity & & $\begin{array}{c}0.121 \\
(0.047)\end{array}$ & & $\begin{array}{c}0.137 \\
(0.047)\end{array}$ & $\begin{array}{c}0.103 \\
(0.043)\end{array}$ \\
\hline Informal team diversity & & & $\begin{array}{c}1.242 \\
(0.330)\end{array}$ & $\begin{array}{c}1.272 \\
(0.317)\end{array}$ & $\begin{array}{c}0.725 \\
(0.166)\end{array}$ \\
\hline Year FEs & Yes & Yes & Yes & Yes & Yes \\
\hline Product group FEs & Yes & Yes & Yes & Yes & Yes \\
\hline Observations & 121 & 121 & 121 & 121 & 121 \\
\hline
\end{tabular}

Robust standard errors in parentheses

Note: We used the generalized linear model with Poisson family and the iterative reweighted least square option with robust standard errors to implement these models. All results remained robust to using OLS with robust standard errors. 
Table 3. Results of Bootstrapping Mediation Regression Analysis for Relationships between Team Diversity, Patent Application Scope, and Patent Approval Speed

\begin{tabular}{|c|c|c|c|c|c|}
\hline \multirow[b]{2}{*}{ Independent Variables } & \multicolumn{5}{|c|}{$\mathrm{DV}=$ Patent approval speed } \\
\hline & $\mathrm{B}$ & SE & $95 \% \mathrm{CI}$ & $\begin{array}{l}\text { Robust in } \\
\text { Sobel Test }\end{array}$ & $\begin{array}{c}\text { Robust in } \\
\text { Goodman } \\
\text { Test }\end{array}$ \\
\hline \multicolumn{6}{|l|}{$\begin{array}{l}\text { Indirect Effects mediated by patent } \\
\text { application scope }\end{array}$} \\
\hline Formal team diversity & -0.013 & 0.006 & $-0.024,-0.001$ & Yes & Yes \\
\hline Informal team diversity & -0.138 & 0.043 & $-0.222,-0.052$ & Yes & Yes \\
\hline \multicolumn{6}{|l|}{ Direct Effects } \\
\hline Formal team diversity & -0.026 & 0.013 & $-0.052,0.001$ & - & - \\
\hline Informal team diversity & -0.010 & 0.078 & $-0.163,0.142$ & - & - \\
\hline Patent application scope [total claims] & -0.009 & 0.002 & $-0.012,-0.005$ & - & - \\
\hline \multicolumn{6}{|l|}{ Total Effects } \\
\hline Formal team diversity & -0.039 & 0.013 & $-0.065,-0.013$ & - & - \\
\hline Informal team diversity & -0.148 & 0.078 & $-0.301,0.004$ & - & - \\
\hline Patent application scope [total claims] & -0.009 & 0.001 & $-0.012,-0.005$ & - & - \\
\hline
\end{tabular}

Note: Generalized structural equation modeling fits a single model and estimates both indirect and direct effects (Hayes, 2013; Preacher et al., 2007), in contrast to traditional mediation analysis that involves a series of linear regression models (Baron and Kenny, 1986). A key advantage of this approach is that it allows the residuals to vary (Shaver, 2005). We employed bootstrapping with 500-1,000 replications to test the significance of the indirect paths from the independent variables (formal/informal team diversity) to the dependent variable (patent approval speed) through the mediator (patent application scope) Bootstrapping is a nonparametric approach that imposes no assumptions about the distributions of the variables or the sampling distribution of the statistic. 
Table 4. Moderating Effects of Leader Experience on Relationship between Team Diversity and Patent Application Claims

\begin{tabular}{|c|c|c|c|c|c|}
\hline & \multicolumn{3}{|c|}{$\begin{array}{l}\mathrm{DV}=\text { Patent application scope } \\
\text { [total claims] }\end{array}$} & \multicolumn{2}{|c|}{$\begin{array}{c}\text { DV =Patent application scope } \\
\text { [independent claims] }\end{array}$} \\
\hline & Model 1 & Model 2 & Model 3 & Model 4 & Model 5 \\
\hline Team size & $\begin{array}{c}0.052 \\
(0.025)\end{array}$ & $\begin{array}{c}0.051 \\
(0.025)\end{array}$ & $\begin{array}{c}0.056 \\
(0.025)\end{array}$ & $\begin{array}{c}0.048 \\
(0.016)\end{array}$ & $\begin{array}{c}0.060 \\
(0.015)\end{array}$ \\
\hline Team resource cost & $\begin{array}{l}-0.551 \\
(0.130)\end{array}$ & $\begin{array}{l}-0.533 \\
(0.106)\end{array}$ & $\begin{array}{l}-0.517 \\
(0.110)\end{array}$ & $\begin{array}{l}-0.304 \\
(0.076)\end{array}$ & $\begin{array}{l}-0.305 \\
(0.067)\end{array}$ \\
\hline Team patenting experience & $\begin{array}{c}0.002 \\
(0.002)\end{array}$ & $\begin{array}{c}0.004 \\
(0.003)\end{array}$ & $\begin{array}{c}0.002 \\
(0.002)\end{array}$ & $\begin{array}{c}0.001 \\
(0.002)\end{array}$ & $\begin{array}{l}-0.002 \\
(0.002)\end{array}$ \\
\hline Team returnees & $\begin{array}{c}0.037 \\
(0.047)\end{array}$ & $\begin{array}{c}0.038 \\
(0.045)\end{array}$ & $\begin{array}{c}0.050 \\
(0.051)\end{array}$ & $\begin{array}{l}-0.013 \\
(0.035)\end{array}$ & $\begin{array}{l}-0.013 \\
(0.037)\end{array}$ \\
\hline Formal team diversity & $\begin{array}{c}0.137 \\
(0.047)\end{array}$ & $\begin{array}{c}0.241 \\
(0.057)\end{array}$ & $\begin{array}{c}0.135 \\
(0.048)\end{array}$ & $\begin{array}{c}0.108 \\
(0.038)\end{array}$ & $\begin{array}{c}0.109 \\
(0.049)\end{array}$ \\
\hline Informal team diversity & $\begin{array}{c}1.272 \\
(0.317)\end{array}$ & $\begin{array}{c}1.598 \\
(0.386)\end{array}$ & $\begin{array}{c}1.867 \\
(0.397)\end{array}$ & $\begin{array}{c}0.992 \\
(0.206)\end{array}$ & $\begin{array}{l}1.087 \\
(0.213)\end{array}$ \\
\hline Leader's first patent & & $\begin{array}{c}0.880 \\
(0.322)\end{array}$ & & $\begin{array}{c}0.474 \\
(0.192)\end{array}$ & \\
\hline Formal diversity*leader's first patent & & $\begin{array}{l}-0.233 \\
(0.070)\end{array}$ & & $\begin{array}{l}-0.038 \\
(0.064)\end{array}$ & \\
\hline Informal diversity*leader's first patent & & $\begin{array}{l}-1.004 \\
(0.481)\end{array}$ & & $\begin{array}{l}-0.711 \\
(0.294)\end{array}$ & \\
\hline Leader's first job & & & $\begin{array}{c}1.250 \\
(0.298)\end{array}$ & & $\begin{array}{c}0.961 \\
(0.174)\end{array}$ \\
\hline Formal diversity*leader's first job & & & $\begin{array}{c}-0.222 \\
(0.087)\end{array}$ & & $\begin{array}{l}-0.245 \\
(0.084)\end{array}$ \\
\hline Informal diversity*leader's first job & & & $\begin{array}{l}-2.045 \\
(0.480)\end{array}$ & & $\begin{array}{l}-1.394 \\
(0.286)\end{array}$ \\
\hline Year FEs & Yes & Yes & Yes & Yes & Yes \\
\hline Product group FEs & Yes & Yes & Yes & Yes & Yes \\
\hline Observations & 121 & 121 & 121 & 121 & 121 \\
\hline
\end{tabular}

Robust standard errors in parentheses; Note: We used the generalized linear model with Poisson family and the iterative reweighted least square option with robust standard errors to implement these models. All results are robust to using OLS with robust standard errors. 